\title{
Detection of Biofilm Forming Bacterial Communities from Urinary Catheter of Patients with Change in Its Antibiotic Susceptibility Pattern and Triclosan Effect from Different Hospitals of Amravati City Maharashtra, India
}

\author{
Anjali A. Tiwari*, Niraj Ghnawate \\ Department of Microbiology, Sant Gadge Baba Amravati University, Amravati, India \\ Email: *anjalitiwari2988@gmail.com
}

How to cite this paper: Tiwari, A.A. and Ghnawate, N. (2017) Detection of Biofilm Forming Bacterial Communities from Urinary Catheter of Patients with Change in Its Antibiotic Susceptibility Pattern and Triclosan Effect from Different Hospitals of Amravati City Maharashtra, India. Open Journal of Medical Microbiology, 7, 51-66. https://doi.org/10.4236/ojmm.2017.73005

Received: July 5, 2017

Accepted: September 26, 2017

Published: September 29, 2017

Copyright $\odot 2017$ by authors and Scientific Research Publishing Inc. This work is licensed under the Creative Commons Attribution International License (CC BY 4.0).

http://creativecommons.org/licenses/by/4.0/ (c) (i) Open Access

\begin{abstract}
Purpose: Bacterial biofilm develop on the surfaces of urinary catheter and proceed to cause full blown bacterial infections and sepsis. Urinary catheters, infection rates increase with the duration of catheterization at rates of per day with virtually all of those who undergo long-term catheterization becoming infected. Also antibiotics results in the adaptation and development of resistance leading to treatment failure, prolonged hospitalization, increased costs of care, and increased mortality. Methods: In the present study total 200 used urinary catheters were studied from the different hospitals of Amravati city in 2015-2016. Different bacterial uropathogens were isolated by conventional method and biofilm formation was studied by tissue culture plate (TCP). Antibiotic sensitivity was performed by disc diffusion method. Minimum inhibitory concentration (MIC) and Minimum biofilm eradicating concentration (MBEC) of triclosan was determined by TCP. Results: Out of total samples 93\% are contaminated. Around 59\% urinary catheters contain mixed consortia. Pseudomonas aeruginosa was found to be the strong biofilm forming and multidrug resistant organism. The most effective drug over seven bacteria isolates were chloramphenicol. Triclosan was used to test against the strong and moderate biofilm forming isolates the MIC of triclosan ranged between 1.5 and $1000 \mu \mathrm{g} / \mathrm{ml}$ and MBEC was between 800 and $3200 \mu \mathrm{g} / \mathrm{ml}$ Conclusions: From the study it was concluded that female are more prone to be infected with catheter associated infection. Pseudomonas aeruginosa was found to be deadly caused of infection, as it is highly resistant to antibiotics. Also triclosan showed effective result on the bacterial uropathogens.
\end{abstract}




\section{Keywords}

CAUTI, Biofilm, Uropathogens, Antibiotic Susceptibility, Triclosan

\section{Introduction}

Urinary tract infection (UTI) is one of the most common bacterial infections in humans, with an estimated annual incidence rate of nearly $13 \%$ in women [1] UTIs accounts for $40 \%$ of all nosocomial infections and about $80 \%$ of nosocomial UTIs are related to urethral catheterization [2]. Urethral catheters are indispensible devices which are widely used to measure urine output, collect urine during surgery and manage urethral obstruction [3] [4].

The risk of UTI can be related to the length of time the catheter in place. Most patients catheterized for a week or less would escape from infection, but for the many elderly and disabled patients who are catheterized for several months or years, bacteriuria is inevitable [5]. In addition, several studies showed that antibiotic resistance in UPEC is increasing nowadays [6] [7]. Prolonged urinary tract infections can facilitate the development of catheter biofilm while indwelling (Foley) catheters are effective in relieving urinary retention and managing urinary incontinence, external bacteria have easy access to the bladder, and catheterization can often result in bacteriuria. The phenotype of bacteria in established biofilm is profoundly different from those growing in a planktonic mode [8]. Moreover, increased resistance in this bacteria to antibacterial agents, making systemic antibiotics and antiseptic bladder installations for their elimination from urinary catheter even worse [9] [10].

\subsection{Pathogenesis of Catheter-Associated Biofilm}

Patients with chronic indwelling catheters may have $>105$ viable bacteria per milliliter of urine [11]. These bacteria enter the bladder through the mucosal sheath around the catheter. It is likely that mechanical irritation of the urethral and bladder mucosa by the catheter enhances the susceptibility of these structures to invasion by organisms. Bacteria may be introduced into the bladder of patients with indwelling urinary catheters by three major routes [12] [13]:

1) Introduction at the time of catheter insertion,

2) Migration of bacteria present in the urethra around the catheter,

3) Ascent of bacteria through the lumen of the catheter from a contaminated drainage system.

The development and increased use of closed methods of catheter drainage have contributed to reduction of the latter problem and markedly improved the management of UTI. However, a closed catheter system merely postpones the inevitable; a recent study by [14] showed that bacteriuria began developing in a patient group after the second day, with $100 \%$ of the patients developing bacteriuria by 1 month. Although a small number of urethral bacteria may be intro- 
duced into the bladder when the catheter is inserted, they appear to be washed out by urine flow or are unable to adhere and multiply in the bladder. This is thought to account for the relatively low incidence of bacteriuria after single or intermittent catheterisation. An illuminating study by [15] into the mechanism of bacterial invasion of the urinary tract via devices showed that the intraluminal ascent of bacteria is faster $(32-48 \mathrm{~h})$ than extraluminal ascent $(72-168 \mathrm{~h})$. Colonisation of the luminal surface, particularly of urinary devices, has been shown in a number of studies [16] [17] [18]. Adherence of bacteria to the device surface is the first step in infection, but our understanding of the cause of this interaction is important for prevention of device-related infection. [19] [20] has shown that planktonic bacteria can produce signalling molecules such as acylated homoserine lactones with the ability to absorb to surfaces, thereby serving to attract the bacteria. Gene expression can also be triggered [21] embedded within the confluent glycocalyx. During the critical stage in attachment of reversible adherence, the bacterial cells can upregulate specific adhesion genes. Then, in order to ensure their successful colonisation of the surface, extrapolymeric substances, chiefly exopolysaccharide, are synthesised to provide a protective glycocalyx as the fledgling community of a new biofilm develops. Rapidly dividing bacteria can spread along the surface of a device within the glycocalyx of the biofilm. Some of the surface bacteria can be shed and become free to attach to a new, non-colonised surface [22] [23].

The catheter helps to connect the heavily colonized perineum with the sterile bladder, thus providing a route for bacterial entry into the bladder. For example P. mirabilis, Providenncia stuartii, Morganella morganii and $K$. pneumonia produce urease and form a unique type of crystalline biofilm on catheters [24]. Urease production by these organisms enables them to break down the urea in urine [25] [26] and release ammonia, which raises the urine $\mathrm{pH}$ resulting in calcium and magnesium phosphate crystal formation within the biofilm matrix [27]. The crystal formation is medically significant because of the blockage of catheters due to crystallization and encrustation, which can lead to bladder distension, pyelonephritis when urine from the distended bladder reluxes into the kidney. Additionally crystalline biofilm that form on the outside of the catheter can lead to irritation and trauma of the urethral mucosa [28] [29]. Urine pools in the bladder or in the catheter results into urinary stasis that promotes bacterial growth. Additionally, the catheter also damages the bladder mucosa by triggering inflammatory response and mechanical erosion [30]. Once bacteria gain entry into the urinary tract, low level bacteriuria progresses within 24 to $48 \mathrm{~h}$ in the absence of an antimicrobial therapy [31] [32] [33].

The biofilm is a complex unit. It can be up to 500 cells deep, but may only be composed of a small percentage of bacterial cells with the remainder being comprised of extrapolymeric substances. Within the urinary tract, the matrix may also contain large quantities of encrusting minerals [34]. Microcolonies of bacterial cells are found within the biofilm matrix, and water filled channels ob- 
served within the system may allow ingress of nutrients and removal of waste products and toxins [35]. The nature of a biofilm indicates how increased resistance is achieved in comparison to the planktonic counterpart. Another very important characteristic of the bacteria within the biofilm is the ability to grow and metabolize at very different rates at different locations in the same biofilm. It has been shown that bacterial growth can be slow or almost absent [36]. Consequently, the potency of antibiotics is reduced significantly if their mode of action is dependent on bacterial growth. Bacteria within a biofilm are $50-500$ times more resistant to antibiotics than their planktonic counterparts [37] [38]. In the manner that stationary growth phase bacteria are more resistant to many antibiotics than are logarithmic phase cells, bacteria become significantly more resistant immediately after they adhere to a surface and subsequently increase this resistance over the ensuing days of biofilm formation [39].

\subsection{Triclosan}

Triclosan is a broad-spectrum hydrophobic antimicrobial agent. Because of its favorable safety profile, Triclosan has been used for the past 2 decades in several dermatological preparations and oral hygiene products. Results of toxicology studies show that triclosan and its metabolites are well tolerated by a variety of species, including human beings [40] [41] [42] [43].

Triclosan is a synthetic, broad-spectrum antimicrobial agent. It has been available in the market for about four decades. Medical uses of it include: eradication of methicillin-resistant Staphylococcus aureus (MRSA) in patients by reducing skin colonization [44], skin and wounds disinfection, oral hygiene products to control dental plaque accumulation and gingivitis. It is also used in a wide variety of cosmetic products, fabrics, plastics and other products to prevent deterioration due to microbes. Triclosan is present in many consumer products and brands which includes: soap and dishwashing liquid, towels, mattresses, sponges, personal care products, shower curtains, deodorants, toothbrushes, phones, kitchenware and plastic food containers, shoes, flooring and carpets, cutting boards, clothing and fabrics, children's toys and many other consumer products [45]. Triclosan possesses antibacterial properties along with antifungal and antiviral activities [45]. Using a very strong antimicrobial agent such as triclosan domestically or in everyday use causes more harm than benefits. Many antimicrobial treatments are toxic detrimental method to eradicate all microorganisms to which they are applied. This approach includes the risk of toxicity to host organisms, that is, the plants or animals (including humans) exposed to treatment for microbial infections. Also, it could be toxic to humans when food items, kitchen wares, objects and surfaces are treated with antimicrobials. Use of triclosan or other antimicrobials can also destroy the beneficial bacteria which occur naturally in the environment and in our bodies [FSNET, 2000]. These friendly bacteria cause no harm but produce beneficial effects such as aiding metabolism and inhibiting the invasion of harmful pathogens [46]. Constant 
exposure to triclosan can also cause genetic mutations resulting in drug-resistant bacteria, which are harmful microbes that are more resistant [47]. Also, According to United States Food and drug Administration [2010], there is no evidence that triclosan provides extra benefits to health in consumer products except in tooth paste where it prevents gingivitis.

\subsection{Mechanism of Action of Triclosan}

Triclosan acts by blocking the active site of the enoyl-acyl carrier protein reductase enzyme (ENR), which is an essential enzyme in fatty acid synthesis in bacteria [48] [49]. By blocking the active site, triclosan inhibits the enzyme, and therefore prevents the bacteria from synthesizing fatty acid, which is necessary for building cell membranes, for keeping the selective permeability and for reproducing [48] [49]. Triclosan is a very potent inhibitor of ENR. Triclosan binds to bacterial enoyl-acyl carrier protein reductase enzyme (ENR), which is encoded by the gene FabI. This binding increases the enzyme's affinity for nicotinamide adenine dinucleotide (NAD+). These results to formation of a stable ENRNAD+- triclosan complex, and only low concentrations are needed for powerful bactericidal action [50]. Humans do not have this ENR enzyme, and are therefore not affected.

The present study was carried out to know the incidence of catheter associated nosocomial infections in the Hospitals of Amravati, Maharashtra State, India in 2015-2016. The study focuses on isolation and identification of nosocomial bacterial uropathogens from urinary catheters and detection of biofilm formation of the isolated uropathogens by Tissue culture plate (TCP) method. Furthermore, the antibiotic susceptibility of the uropathogens was studied against the different class of antibiotics and effect of triclosan on strong and moderate biofilm forming isolates by three different methods disc diffusion, MIC and MBEC by TCP.

\section{Methodology}

\subsection{Study Design}

A retrospective analysis of culture results of used urinary catheter was performed at Department of Microbiology at Sant Gadge Baba Amravati University. The sex, age and duration of catheterization of patients, the organism isolated, biofilm forming ability, antimicrobial susceptibility profiles and effect of triclosan were studied. All experiment assays were performed independently and in triplicate.

\subsection{Sample Collection and Processing}

A total of 200 used urinary catheters from different hospitals were collected from Amravati city in sterilized HiDispoTM bag [HiMedia Laboratories Pvt. Ltd.] in aseptic condition. The urinary catheter was immediately brought to the laboratory and was processed in aseptic conditions. The collected urinary catheters were washed with sterile distilled water and flushed with saline solution than 
swabbed with $70 \%$ alcohol swab from outer side of the catheter to remove planktonic bacteria. and were then sectioned into five appropriate parts A, B, C, $\mathrm{D}, \mathrm{E}$ from tip and each part were suspended into test tubes containing sterile Ringer's solution (10ml) separately. Sonication for 5 minutes at $35 \mathrm{kHz}$ in water bath and vortex mixing for 2 minutes were performed to remove and disrupt the colonizing biofilm.

\subsection{Isolation and Identification of Uropathogens}

Resulting cell suspensions were cultured by taking a loopful of suspension on to Hi-chrome UTI agar plates [51] [HiMedia Laboratories Pvt. Ltd.] The plates after streaking were incubated at $37^{\circ} \mathrm{C}$ for $24 \mathrm{~h}$. The colored colonies were observed \& identified on the basis of morphological, cultural \& biochemical test. Some bacterial cultures that were could not be identified by conventional method were identified by VITEK automated identification method [BioMerieux VITEK 2 Compact].

\subsection{In vitro Antibiotic Susceptibility of Uropathogens}

Antibiotic susceptibility testing against isolates was performed according to Kirby Bauer's method and interpreted as per Clinical and Laboratory Standards Institute (CLSI) recommendations (CLSI, 2005). The antibiotic discs (Himedia, India) used were Amikacin $(30 \mu \mathrm{g})$, Amoxicillin $(30 \mu \mathrm{g})$, Cefaclor $(30 \mu \mathrm{g}), \mathrm{Ce}-$ fixime $(30 \mu \mathrm{g})$, Ceftriaxone $(30 \mu \mathrm{g})$, Chloramphenicol $(30 \mu \mathrm{g})$, Ciprofloxacin $(5$ $\mu \mathrm{g})$, Gatifloxacin $(5 \mu \mathrm{g})$, Nalidixic acid $(30 \mu \mathrm{g})$, Nitrofurantoin $(300 \mu \mathrm{g})$, Piperacillin $(100 \mu \mathrm{g})$ and Vancomycin $(30 \mu \mathrm{g})$. Antibiotics were stored as per the manufacturer's recommendations. Each experiment was performed in triplicates.

\subsection{Detection of Biofilm Formation by TCP Method [52]}

Organisms isolated from fresh agar plates were inoculated in $10 \mathrm{ml}$ of trypticase soy broth with $1 \%$ glucose. Broths were incubated at $37^{\circ} \mathrm{C}$ for $24 \mathrm{~h}$. The cultures were then diluted 1:100 with fresh medium. Individual wells of sterile 96 well flat bottom polystyrene tissue culture treated plates were filled with $200 \mu \mathrm{l}$ of the diluted cultures. The control organisms were also incubated, diluted and added to tissue culture plate. Negative control wells contained inoculated sterile broth. The plates were incubated at $37^{\circ} \mathrm{C}$ for $24 \mathrm{~h}$ after incubation; contents of each well were removed by gentle tapping. The wells were washed with $0.2 \mathrm{ml}$ of phosphate buffer saline ( $\mathrm{pH}$ 7.2) four times. This removed free floating bacteria. Biofilm formed by bacteria adherent to the wells were fixed by $2 \%$ sodium acetate and stained by crystal violet $(0.1 \%)$. Excess stain was removed by using deionised water and plates were kept for drying. Optical density (OD) of stained adherent biofilm was obtained by using micro ELISA auto reader at wavelength $570 \mathrm{~nm}$. Experiment was performed in triplicate [41]. Results were interpreted as per Table 1. 
Table 1. Standard reference table for measurement of biofilm formation.

\begin{tabular}{ccc}
\hline Mean OD values & Adherence & Biofilm formation \\
\hline$<0.120$ & Non & Non/weak \\
$0.120-0.240$ & Moderately & Moderate \\
$>0.240$ & Strong & High \\
\hline
\end{tabular}

\subsection{Three Different Methods for Triclosan}

\subsubsection{Disc Diffusion Method [53]}

Disk diffusion AST (Antimicrobial susceptibility test) is also referred to as the Kirby-Bauer method, the top portion of three to five, 18 to $24 \mathrm{~h}$ old, well isolated, colonies transferred to a tube containing broth medium. The broth culture is incubated at $35^{\circ} \mathrm{C}$ until the turbidity of the culture meets the turbidity of a 0.5 McFarland turbidity standard. Inoculation of the $\mathrm{MH}$ agar plate is accomplished as described by the CLSI. In essence, it involves swabbing the entire surface of the plate three times, in three different directions, to ensure that the organism grows over the entire surface of the plate. Small filter paper disks, each containing a triclosan an antimicrobial agent, are then placed on the agar surface, making sure that the entire lower surface of each disk is in contact with the agar surface. The plate is then inverted and incubated for 16 to $18 \mathrm{~h}$ at $35^{\circ} \mathrm{C}$ in an incubator. During the incubation period, the drug diffuses into the agar After 16 to $18 \mathrm{~h}$ of incubation, the plate is removed from the incubator, and the diameter of each zone of no growth is carefully measured in millimeters.

\subsubsection{Minimum Inhibitory Concentration (MIC) by Agar Dilution}

The Triclosan to be tested is added to Muller Hinton (MH) agar, which is then placed in dilution plates and diluted with varying levels of water. After this, the pathogen to be tested is added to each plate, plus a control plate that does not receive Triclosan. The dilution plates are then incubated at $37^{\circ} \mathrm{C}$. The plates are then incubated for $24 \mathrm{~h}$, although incubation time may be less for bacteria populations that divide quickly. After incubation, the plates are examined to determine if bacterial expansion has occurred. The lowest concentration of Triclosan that stopped the spread of the bacteria is considered to be the minimum inhibitory concentration of that bacterium.

\subsubsection{Minimum Biofilm Eradicating Concentration by TCP Method [42]}

The MBEC (Minimum biofilm eradicating concentration) Assay can be used to determine the efficacy of an antimicrobial agent against biofilm. The MBEC assay uses a 96-well plate with lid that allow for the adherence and growth of biofilm. MBEC assay is a very time efficient and accurate method of testing antimicrobial agent efficacy against biofilm. In this method take a sterile 96 well Tissue culture plate. In which add fresh trypticase soya broth $(100 \mu \mathrm{L})$ and blank and control well also set up. $1 \mu \mathrm{L}$ bacterial suspension is added into each well except blank and control therefore the mixture is diluted as $1: 100$. Incubated at $37^{\circ} \mathrm{C}$ for 
$48 \mathrm{~h}$. After incubation biofilm is formed in tissue culture plate. Then wash the biofilm plate with phosphate buffer saline for four times. Then add different concentration of Triclosan into each well. Incubated at $37^{\circ} \mathrm{C}$ for $48 \mathrm{~h}$. Again the plate is wash with phosphate buffer saline solution. Add 1\% peptone water in each well and again incubated at $37^{\circ} \mathrm{C}$ for $24 \mathrm{~h}$. Therefore the resistant bacteria can regrow in tissue culture plate. Presence of viable bacteria is determined by streak plate method on Muller-Hinton agar plates. Lowest concentration of Triclosan at which bacteria failed to regrow within a biofilm considered as MBEC.

\section{Results}

\subsection{Urinary Catheters Collection and Durability}

A total of 200 used urinary catheters were collected during the period of study. The urinary catheters were collected from the patients at different hospitals of Amravati region mentioned in Figure 1. It has been observed that the maximum numbers of urinary catheters were contaminated by nosocomial pathogens suggesting septic conditions of the particular hospital, handling care of catheter by patients and the duration of catheterization. During the study only $7 \%$ of samples were found to be of no bacterial growth.

It was observed that the female catheterized patients are more prone to infection as the catheter get contaminated with in less period of time as compare to male patients though the number of male catheter samples was more but the more frequently contamination were observed in the female catheterized patients. The maximum contaminations were observed in urinary catheters of males and females with duration of 6 - 10 days and 26 - 30 (Figure 1).

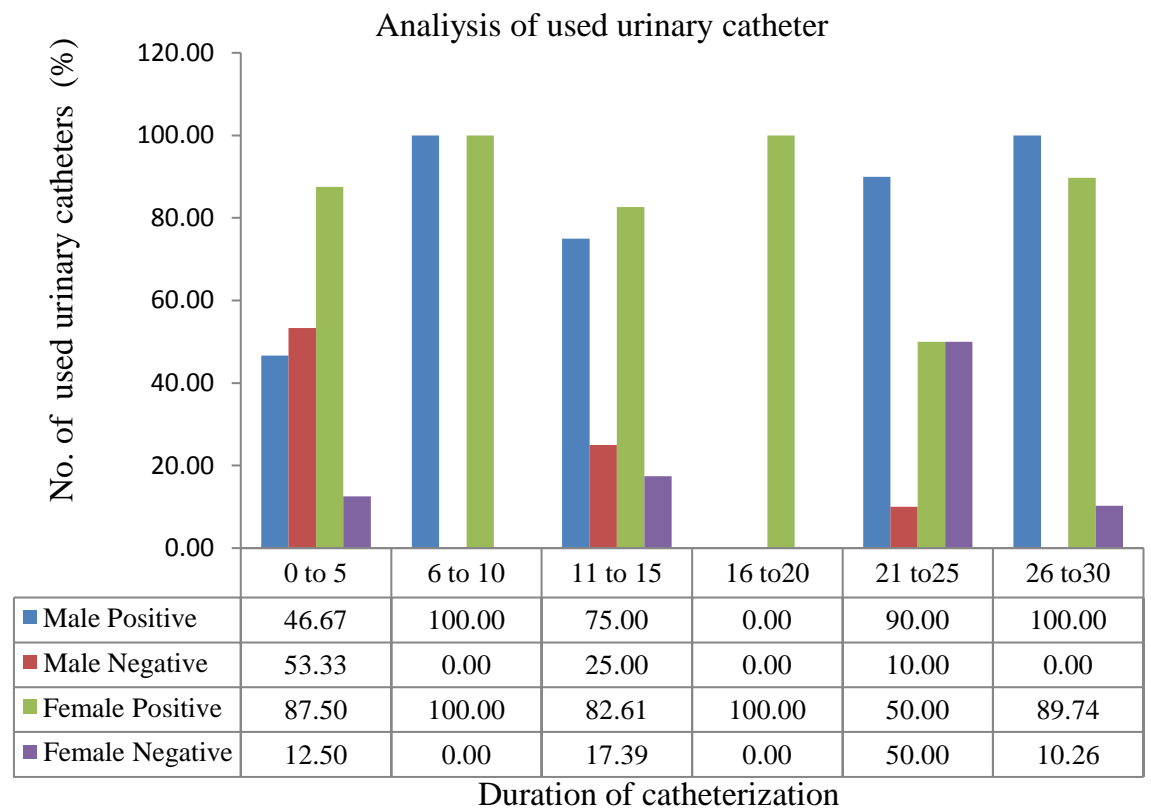

Figure 1. Analysis of factors associated with CAUTI. 


\subsection{Isolation, Identification and Biofilm Formation of Uropathogens}

In present study total 368 bacterial uropathogens were isolated from 200 urinary catheters. Out of which strains of different bacterial species were identified by using conventional methods and through VITEK2 automated identification.

TCP the standard method is used to detect biofilm formation of the isolates, Pseudomonas aeruginosa (41.84\%) Enterococcus faecalis (19.02\%) and Staphylococcus aureus (16.84\%) were strong biofilm forming. No species of Escherichia coli were found to be of strong biofilm forming explained in Figure 2. During the study 59\% (118 specimens) used urinary catheter was found with multiple bacterial species (Table 2). In the urinary catheter colonized by mixed bacterial species, the major was found to be of Pseudomonas aeruginosa and Enterococ cus faecalis and the least colonized species was Dermacoccus nishmaneyasis. In

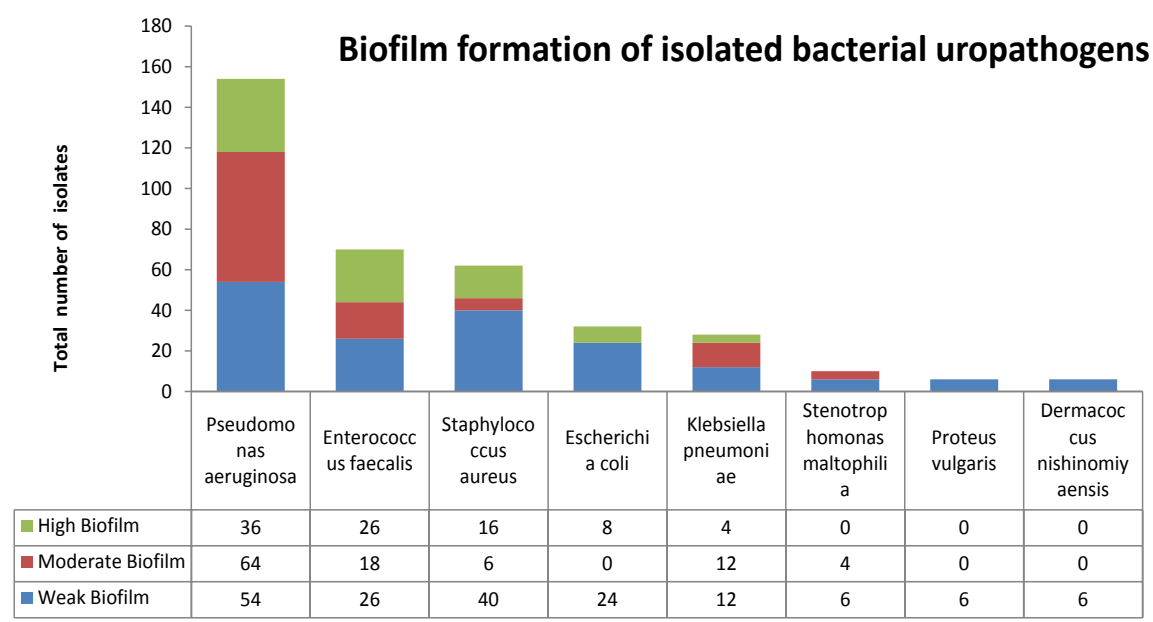

Bacterial uropathogens

Figure 2. Biofilm forming ability of isolated bacterial uropathogens.

Table 2. The incidence of bacterial species isolated from 200 used urinary catheters.

\begin{tabular}{|c|c|c|c|}
\hline \multirow[b]{2}{*}{ Bacterial species } & \multicolumn{3}{|c|}{ Number (\%) of catheters colonized by each species } \\
\hline & $\begin{array}{c}\text { All catheter } \\
\text { bacterial species }\end{array}$ & $\begin{array}{l}\text { Mixed-bacterial species in (118 (59\%) } \\
\text { urinary catheters) }\end{array}$ & $\begin{array}{c}\text { Single-bacterial species in }(82(41 \%) \\
\text { urinary catheters) }\end{array}$ \\
\hline Pseudomonas aeruginosa & $154(77)$ & $94(79.6)$ & $60(73.1)$ \\
\hline Klebsiella pneumonia & $28(14)$ & $28(23.7)$ & $0(0.0)$ \\
\hline Escherichia coli & $32(16)$ & $28(23.7)$ & $4(4.8)$ \\
\hline Stenotrophomonas maltophilia & $10(5)$ & $9(7.6)$ & $1(1.2)$ \\
\hline Proteus vulgaris & $6(3)$ & $6(5.0)$ & $0(0.0)$ \\
\hline Dermacoccus nishinomiyanensis & $6(3)$ & $5(4.2)$ & $1(1.2)$ \\
\hline Enterococcus faecalis & $70(35)$ & $58(49.1)$ & $12(14.6)$ \\
\hline Staphylococcus aureus & $62(31)$ & $57(48.0)$ & $5(6.0)$ \\
\hline
\end{tabular}


the similar manner, major bacterial colony species were same to the urinary catheter colonized by single bacterial species but the least species was observed that of stenotrophomonas maltophilia and Dermacoccus nishmaneyasis.

\subsection{Antimicrobial Susceptibility of Bacterial Isolates from Used Urinary Catheters}

The predominant growth of single bacteria was seen in $41 \%$ used urinary catheters. More than $60 \%$ of the isolates were sensitive to amikacin around $45 \%$ of the isolates were sensitive to ciprofloxacin and Gatifloxacin (Table 3 and Table 4). Amoxycillin was found the most resistant drug in all the isolated pathogens only susceptible to Proteus vulgaris, Enterococcus fecalis and Staphylococcus aureus.

Escherichia coli, P aeruginosa, Enterococcus fecalis, and Staphylococcus aureus susceptibile to ciprofloxacin, amikacin, Gatifloxacin ceftriaxone followed by Gatifloxacin which showed high sensitivity against Klebsiella further Stenotrophomonas maltophilia was found to be equally susceptible to only four antibiotics i.e. amikacin, chloramphenicol, gatifloxacin, Nitrofurantoin. Proteus vulgaris completely sensitive to all the antibiotics equally and no resistant were observed. Dermacoccus nishmaneyasi rare species were highly susceptible to chloramphenicol, ciprofloxacin, gatifloxacin, nalidixic acid and resistant to all other antibiotics. Enterococcus faecalis resistant to Cefixime (Table 3 and Table 4).

\subsection{Triclosan}

As per our primary study Triclosan has shown lots of promising effects over eradication and prevention of biofilm in urinary catheter. The MIC of triclosan

Table 3. Antibiogram of Pseudomonas aeruginosa $(\mathrm{n}=154)$, Klebsiella pneumonia $(\mathrm{n}=28)$, Escherichia coli $(\mathrm{n}=32)$, Stenotrophomonas maltophilia $(\mathrm{n}=10)$ isolates from used urinary catheters of hospitals of Amravati city in 2015-2016.

\begin{tabular}{|c|c|c|c|c|c|c|c|c|}
\hline \multicolumn{9}{|c|}{ Number (\%) susceptible and resistance of each species } \\
\hline \multirow{2}{*}{ Antimicrobial agent } & \multicolumn{2}{|c|}{$\begin{array}{l}\text { Pseudomonas aeruginosa } \\
\qquad(\mathrm{n}=154)\end{array}$} & \multicolumn{2}{|c|}{$\begin{array}{l}\text { Klebsiella pneumonia } \\
\qquad(\mathrm{n}=28)\end{array}$} & \multicolumn{2}{|c|}{$\begin{array}{l}\text { Escherichia coli } \\
\qquad(\mathrm{n}=32)\end{array}$} & \multicolumn{2}{|c|}{$\begin{array}{l}\text { Stenotrophomonas } \\
\text { maltophilia }(\mathrm{n}=10)\end{array}$} \\
\hline & Susceptible & Resistant & Susceptible & Resistant & Susceptible & Resistant & Susceptible & Resistant \\
\hline Amikacin & $84(54.5)$ & $70(45.5)$ & $18(64.2)$ & $10(35.7)$ & $24(75)$ & $8(25)$ & $4(40)$ & $6(60)$ \\
\hline Amoxycillin & $0(0.0)$ & $154(100)$ & $0(0.0)$ & $28(100)$ & $0(0.0)$ & $32(100)$ & $0(0.0)$ & $10(100)$ \\
\hline Cefaclor & $22(14.2)$ & $132(85.7)$ & $6(21.4)$ & $22(78.5)$ & $0(0.0)$ & $32(100)$ & $0(0.0)$ & $10(100)$ \\
\hline Cefixime & $16(10.3)$ & $138(89.6)$ & $4(14.2)$ & $24(85.7)$ & $0(0.0)$ & $32(100)$ & $0(0.0)$ & $10(100)$ \\
\hline Ceftriaxone & $36(23.3)$ & $118(76.6)$ & $4(14.2)$ & $24(85.7)$ & $20(62.5)$ & $12(37.5)$ & $0(0.0)$ & $10(100)$ \\
\hline Chloramphenicol & $30(19.4)$ & $126(81.8)$ & $24(85.7)$ & $4(14.2)$ & $14(43.7)$ & $18(56.2)$ & $4(40)$ & $6(60)$ \\
\hline Gatifloxacin & $50(32.46)$ & $104(67.5)$ & $28(100)$ & $0(0.0)$ & $24(75)$ & $8(25)$ & $4(40)$ & $6(60)$ \\
\hline Nalidixic acid & $6(3.8)$ & $148(96.1)$ & $4(14.2)$ & $24(85.7)$ & $6(18.7)$ & $26(81.2)$ & $0(0.0)$ & $10(100)$ \\
\hline Nitrofurantoin & $4(2.5)$ & $150(97.4)$ & $14(50)$ & $14(50)$ & $24(75)$ & $8(25)$ & $4(40)$ & $6(60)$ \\
\hline Piperacillin & $22(14.2)$ & $132(85.7)$ & $4(14.2)$ & $24(85.7)$ & $0(0.0)$ & $32(100)$ & $0(0.0)$ & $10(100)$ \\
\hline
\end{tabular}


Table 4. Antibiogram of Proteus vulgaris $(\mathrm{n}=6)$, Dermacoccus nishmaneyasis $(\mathrm{n}=6)$, Enterococcus faecalis $(\mathrm{n}=70)$, Staphylococcus aureus $(\mathrm{n}=62)$ isolates from used urinary catheters of hospitals of Amravati city in 2015-2016.

\begin{tabular}{|c|c|c|c|c|c|c|c|c|}
\hline \multirow{3}{*}{$\begin{array}{l}\text { Antimicrobial } \\
\text { agent }\end{array}$} & \multicolumn{8}{|c|}{ Number (\%) susceptible and resistance of each species } \\
\hline & \multicolumn{2}{|c|}{ Proteus vulgaris $(\mathrm{n}=6)$} & \multicolumn{2}{|c|}{$\begin{array}{l}\text { Dermacoccus nishinomiyanensis } \\
\qquad(\mathrm{n}=6)\end{array}$} & \multicolumn{2}{|c|}{ Enterococcus faecalis $(\mathrm{n}=70)$} & \multicolumn{2}{|c|}{ Staphylococcus aureus $(\mathrm{n}=62)$} \\
\hline & Susceptible & Resistant & Susceptible & Resistant & Susceptible & Resistant & Susceptible & Resistant \\
\hline Amikacin & $6(100)$ & $0(0.0)$ & $0(0.0)$ & $6(100)$ & $48(68.5)$ & $22(31.4)$ & $40(64.5)$ & $22(35.4)$ \\
\hline Amoxycillin & $6(100)$ & $0(0.0)$ & $0(0.0)$ & $6(100)$ & $18(25.7)$ & $52(74.2)$ & $12(19.3)$ & $50(80.6)$ \\
\hline Cefaclor & $6(100)$ & $0(0.0)$ & $0(0.0)$ & $6(100)$ & $20(28.5)$ & $50(71.4)$ & $0(0.0)$ & $62(100)$ \\
\hline Cefixime & $6(100)$ & $0(0.0)$ & $0(0.0)$ & $6(100)$ & $0(0.0)$ & $70(100)$ & $6(9.6)$ & $56(90.3)$ \\
\hline Ceftriaxone & $6(100)$ & $0(0.0)$ & $0(0.0)$ & $6(100)$ & $31(44.2)$ & $39(55.7)$ & $27(43.5)$ & $35(56.4)$ \\
\hline $\begin{array}{l}\text { Chlorampheni- } \\
\text { col }\end{array}$ & $6(100)$ & $0(0.0)$ & $6(100)$ & $0(0.0)$ & $40(57.1)$ & $30(42.8)$ & $22(35.4)$ & $40(64.5)$ \\
\hline Ciprofloxacin & $6(100)$ & $0(0.0)$ & $6(100)$ & $0(0.0)$ & $34(48.5)$ & $36(51.4)$ & $35(56.4)$ & $27(43.5)$ \\
\hline Gatifloxacin & $6(100)$ & $0(0.0)$ & $6(100)$ & $0(0.0)$ & $24(34.2)$ & $46(65.7)$ & $28(45.1)$ & $34(54.8)$ \\
\hline Nalidixic acid & $6(100)$ & $0(0.0)$ & $6(100)$ & $0(0.0)$ & $32(45.7)$ & $38(54.2)$ & $28(45.1)$ & $34(54.8)$ \\
\hline Nitrofurantoin & $6(100)$ & $0(0.0)$ & $0(0.0)$ & $6(100)$ & $24(34.2)$ & $46(65.7)$ & $24(38.7)$ & $38(61.2)$ \\
\hline Piperacillin & $6(100)$ & $0(0.0)$ & $0(0.0)$ & $6(100)$ & $26(37.1)$ & $44(62.8)$ & $12(19.3)$ & $50(80.6)$ \\
\hline
\end{tabular}

ranged between 1.5 to $1000 / \mathrm{ml}$ and MBEC was between 800 to $3200 \mu / \mathrm{ml}$ i.e. $\mathrm{BEC}$ values were 3 to 1800 folds than MIC values. This in vitro antimicrobial activity of triclosan is mentioned in Figure 3 and Figure 4 for its in vivo profile against all catheter associated urinary tract infection needs further investigation up till now triclosan is our prime choice against uropathogens.

\section{Discussion}

Present study revealed that, indwelling urinary catheter gets contaminated by various nosocomial pathogens during the course of catheterization. Contamination also depends on the gender of patient. Female catheter are more prone to get contaminated around $95.83 \%$ female patients urinary catheter was contaminated. Duration of catheterization also influences of contamination. Maximum catheters are of 26 - 30 days contamination of urinary catheter is also related to biofilm forming ability of the contaminants. If the bacteria are biofilm producer, there is more risk of its persistence and subsequent infection. Thus it was concluded that $93 \%$ of catheter gets contaminated during course of catheterization. $52.7 \%$ contaminants are biofilm forming

Similarly, Abdallah and Balasubramanian, [42] screened 45 urinary catheters and found that out of 37 were found with a biofilm forming bacterial pathogens and over 25 days or months had a dense biofilm matrix seven species of microbial strains were isolated from the biofilm matrix and different bacteria that constituted the biofilm revealed that the Escherichia coli incidence was high (27\%) followed by Proteus mirabilis (20\%), Staphylococcus epidermis (18\%) and Staphylococcus aureus (16\%). 


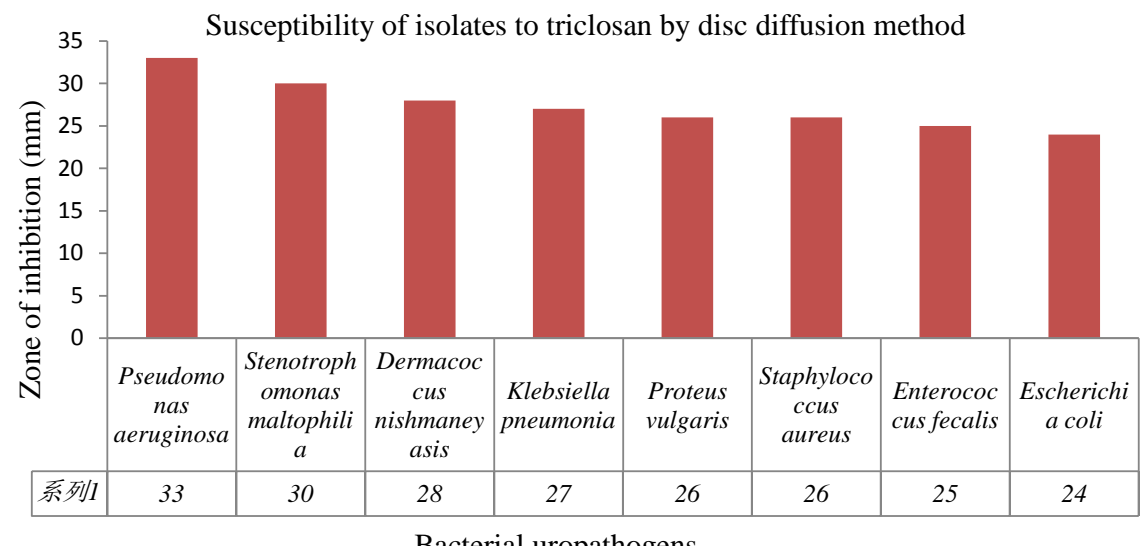

Bacterial uropathogens

Figure 3. Antibacterial susceptibility of triclosan against isolated bacterial uropathogens.

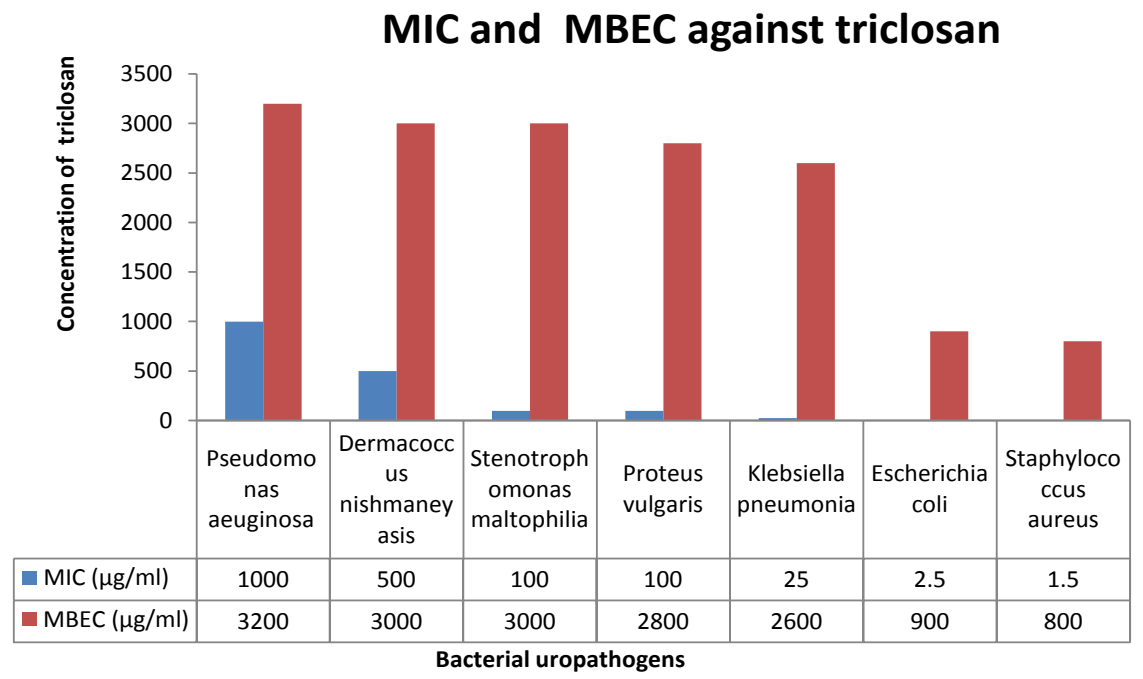

Figure 4. Comparison of MIC and MBEC for isolated bacterial uropathogens.

Also Taiwo and Aderounmu, found that Klebsiella spp were the commonest pathogen isolated with 46 (36.6\%), followed by Pseudomonas spp 34 (27.0\%), Escherichia coli 26 (20.6\%), Staphylococcus aureus 12 (9.5\%), Proteus mirabilis 4 (3.2\%), Candida albicans 4 (3.2\%) and coagulase negative staphylococci 2 (1.6\%). But in present study Pseudomonas aeruginosa was the commonest contaminant organism were found and two rare species of bacteria were also obtained Stenotrophomonas maltophilia and Dermacoccus nishinomiyaensis. Out of total 59\% urinary catheters contains mixed consortia of bacteria in the present investigation.

In present study it was found that susceptibility profile shows multiple drug resistance among most of the biofilm forming isolates. Pseudomonas aeruginosa was found to be the most multidrug resistant organism. The most effective drug which were effective over seven bacterial isolates were chloramphenicol and gatifloxacin while amikacin, ciprofloxacin, nalidixic acid and nitofurantoin were effective over 6 isolated microorganisms which was followed by Ceftriaxone and Piperacillin which were found to be effective over five bacterial isolates. The least 
effective drug was amoxycillin, cefaclor and cefixime (Table 3 and Table 4).

Reiter and Rajamoha, found that frequency of UTI was greater in women as compared to men as $66 \%$ of the patients were females and $34 \%$ were male it was observed that as the no. of male samples are more but the contaminated samples are more of female catheterized patient . Duration of catheterization is one of the leading reasons for the catheterized infection during the sampling it was observed that as longer the duration there is more chances of infection and blockage of the urinary catheter. Abdallah, Taiwo and Aderounmu observed that period ranging from 48 hours to over 28 days before change or removal and all were routinely placed on prophylactic systemic antibiotic following catheterization Pseudomonas aeruginosa among the three aminoglycosides, amikacin showed $72 \%$ susceptibility and in the present work it was observed that only $54.5 \%$ susceptible.

Enterococcus isolates were studied by Sivraj et al. total 68 species where checked for antibiotic resistance and found that high rates of resistance to ciprofloxacin, rifampicin and erythromycin were as in present study Enterococcus were completely resistant to cefixime. Also Koshariya were found that isolated Escherichia coli from urinary catheter were resistant to amoxicillin $58.7 \%$, cefixime $83.6 \%$ but in the present study, it shows $100 \%$ resistance to amoxicillin, cefixime, piperacillin and cefaclor. During the present investigation two rare bacterial species was identified Dermacoccus nishmaneyasis and Stenotrophomonas maltophilia isolated from the urinary catheter sample. Similarly Mengegloglu et al. isolated Stenotrophomonas maltophilia from the three different sources respiratory tract followed by blood and wounds.

\section{Conclusion}

In the present study the number of catheter sample is more of male than female, but the bacterial contaminations were more observed in the female catheterized patients. Also the duration of catheterization is one of the important factors which is the main cause of contamination observed that as the patient get catheterized for longer duration the more is the encrustation and formation of slime layer inside the lumen of catheter. The main contaminant found was strong biofilm forming Pseudomonas aeruginosa highest in number among all single and multi species contaminated catheters sample of catheterized patients. During the study, two rare species Dermacoccus nishinomiyaensis and Stenotrophomonas maltophilia both show resistance to all other antibiotics except chloramphenicol and gatifloxacin. Triclosan used against strong and moderate biofilm forming isolates are very good. Minimum concentration is required for the inhibition of planktonic bacterial growth as performed by disc diffusion and MIC by TCP method and the concentration required for MBEC is higher than that of MIC values. The MIC of triclosan ranged between 1.5 and $1000 \mu / \mathrm{ml}$ and MBEC was between 800 and $3200 \mu / \mathrm{ml}$ i.e. MBEC values were 3 to 1800 folds than MIC values.

This work was supported by funds from the University Grants Commission (UGC) [F.No 43-472/2014 (SR)], New Delhi, India, under the Major research project. 


\section{References}

[1] Foxman, B. (2010) The Epidemiology of Urinary Tract Infection. Nature Reviews Urology, 7, 653-660. https://doi.org/10.1038/nrurol.2010.190

[2] Johnson, J.R. (2006) Systematic Review: Antimicrobial Urinary Catheters to Prevent Catheter Associated Urinary Tract Infections in Hospitalized Patients. Annals of internal Medicine, 144, 116-126. https://doi.org/10.7326/0003-4819-144-2-200601170-00009

[3] Donlan, R.M. and Costerton, J.W. (2002) Survival Mechanisms of Clinically Relevant Microorganisms. Clinical Microbiology Reviews, 15, 167-193.

https://doi.org/10.1128/CMR.15.2.167-193.2002

[4] Nickel, J.C. (1994) Bacterial Biofilms: Influence on the Pathogenesis, Diagnosis and Treatment of Urinary Tract Infections. Journal of Antimicrobial Xhemotherapy, 33, 31-41. https://doi.org/10.1093/jac/33.suppl A.31

[5] Hachem, R., Reitzel, R., Borne, A., Jiang, Y., Tinkey, P., Uthamanthil, R., Chandra, J., Ghannoum, M. and Raad, I. (2009) Novel antiseptic Urinary Catheters for Prevention of Urinary Tract Infections: Correlation of in vivo and in vitro Test Results. Antimicrob Agent Chemother, 53, 5145-5149. https://doi.org/10.1128/AAC.00718-09

[6] Warren, J.W. (1991) The Catheter and Urinary Tract Infection. Medical Clinics of North America, 75, 481-493.

[7] Costerton, J.W. (1995) Microbial Biofilms. Annual Review of Microbiology, 49, 711-745. https://doi.org/10.1146/annurev.mi.49.100195.003431

[8] Clayton, C.L., Chawla, J.C. and Stickler, D.J. (1982) Some Observations on Urinary Tract Infections in Patients Undergoing Long-Term Bladder Catheterization. Journal of Hospital Infection, 3, 39-47.

[9] Ganderton, L. (1992) Scanning Electron Microscopy of Bacterial Biofilms on Indwelling Bladder Catheters. European Journal of Clinical Microbiology \& Infectious Diseases, 11, 789-797. https://doi.org/10.1007/BF01960877

[10] Stickler, D.J., Clayton, C.L. and Chala, J.C. (1987) The Resistance of Urinary Tract Pathogens to Chlorhexidine Bladder Washouts. Journal of Hospital Infection, 10, 219-228. https://doi.org/10.1016/0195-6701(87)90001-6

[11] Johnson, J.R. (2005) Virulence Genotype and Phylogenetic Origin in Relation to Antibiotic Resistance Profile among Esherichia Coli Urine Sample Isolates from Israeli Women with Acute Uncomplicated Cystitis. Antimicrobial Agents and Chemotherapy, 49, 26-31. https://doi.org/10.1128/AAC.49.1.26-31.2005

[12] Linde, H.J., Hahn, J., Holler, E., Reischl, U. and Lehn, N. (2002) Septicemia Due to Acinetobacter junii. Journal of Clinical Microbiology, 40, 2696-2697. https://doi.org/10.1128/JCM.40.7.2696-2697.2002

[13] Liedl, B. and Hofstetter, A. (2000) Pathogenesis und verhinderung katheter assoziierter harnwegsinfektionen. Urologie B, 40, 233-237.

https://doi.org/10.1007/s001310050397

[14] Sahm, D.F. (2000) Multidrug Resistant Urinary Tract Isolates of Escherichia Coli: Prevalence and Patient Demographics in the United States in 200. Antimicrobial Agents and Chemotherapy, 42, 1402-1406.

[15] Nys, S., Van Merode, T., Bartelds, A.L. and Stobberingha, E.E. (2006) Antibiotic Treatment and Resistance of Unselected Uropathogens in the Elderly. International Journal of Antimicrobial Agents, 27, 236-241. https://doi.org/10.1016/j.ijantimicag.2005.10.015

[16] Karlowsky, J.A., Hoban, D.J., Decorby, M.R., Laing, N.M. and Zhanel, G.G. (2006) 
Fluoroquinolone-Resistant Urinary Isolates of Escherichia coli from Outpatients Are Frequently Multidrug Resistant: Results from the Norrth American Urinary Tract Infection Collaborative Alliance-Quinolone Resistance Study. Antimicrob Agents Chemother, 50, 225-254. https://doi.org/10.1128/AAC.00123-06

[17] Park, C.H., Robicsek, A., Jacoby, G.A., Sahm, D.F. and Hooper, D.C. (2006) Prevalance in the United States of aac(6')-lb-cr Encoding a Ciprofloxacin-Modifying Enzyme. Antimicrob Agents Chemother, 50, 3953-3955. https://doi.org/10.1128/AAC.00915-06

[18] Johnson, J.R., Johnston, B., Kuskowski, M.A., Colodner, R. and Raz, R. (2005) Spontenous Conversion to Quinolone and Fluoroquinolone Resistance among Wildtype Escherichia coli Isolates in Relation to Phylogenetic Background and Virulence Genotype. Antimicrob Agents Chemother, 49, 4739-4744. https://doi.org/10.1128/AAC.49.11.4739-4744.2005

[19] Lo, E., Nicolle, L., Classen, D., Arias, K.M., Podgorny, K., Anderson, D.J., et al. (2008) Strategies to Prevent Catheter-Associated Urinary Tract Infections in Acute Care Hospitals. Infection Control \& Hospital Epidemiology, 29, S41-50. https://doi.org/10.1086/591066

[20] Costerton, J.W. (1993) Practical Measures to Control Device-Related Bacterial Infections. International Journal of Artificial Organs, 16, 765-770.

[21] Maki, D.G. and Tambyah, P.A. (2001) Engineering Out the Risk for Infection with Urinary Catheters. Emerging Infectious Diseases, 7, 342-347.

[22] Emori, T.G. and Gaynes, R.P. (1993) An Overview of Nosocomial Infections, Including the Role of the Microbiology Laboratory. Clinical Microbiology Reviews, 6, 428-442.

[23] Fuqua, C. and Greenberg, E.P. (1998) Self-Perception in Bacteria: Quorum Sensing with Acylated Homoserine Lactone. Current Option in Microbiology, 1, 183-189.

[24] Gorman, S.P. (2001) The Concomitant Development of Poly (Vinylchloride)-Related Biofilm and Antimicrobial Resistance in Relation to Ventilator-Associated Pneumonia. Biomaterials, 22, 2741-2747.

[25] Li, X. (2002) Visulaization of Proteus mirabilis within the Matrix of Urease-Induced Bladder Stones during Experimental Urinary Tract Infection. Infection and Immunity, 70, 389-394. https://doi.org/10.1128/IAI.70.1.389-394.2002

[26] Mobley, T. and Warren, J.W. (1987) Urease-Positive Bacteriuria and Obstruction of Lone-Term Urinary Catheters. Journal of Clinical Microbiology, 25, 2216-2217.

[27] Stickler, D. (1998) Studies on the Formation of Crystaline Bacterial Biofilms on Urethral Catheters. European Journal of Clinical Microbiology \& Infectious Diseases, 17, 649-652. https://doi.org/10.1007/s100960050150

[28] Hatt, J.K. and Rather, P.N. (2008) Role of Bacterial Biofilms in Urinary Tract Infections. Current Topics in Microbiology and Immunology, 322, 163-192.

[29] Elves, A.W. and Feneley, R.C. (1997) Long-Term Uretheral Catheterization and Urine Biomaterial Interference. British Journal of Urology, 80, 1-5.

[30] Klumpp, D.J., Weiser, A.C., Sengupta, S., Forrestal, S.G., Batler, R.A. and Schaeffer, A.J. (2001) Uropathogenic Escherichia coli Potentiates Type 1 Pilus-Induced Apoptosis by Suppressing NFkappaB. Infection and Immunity, 69, 6689-6695.

[31] Trautner, B.W. and Darouiche, R.O. (2004) Role of Biofilm in Catheter-Associated Urinary Tract Infection. American Journal of Infection Control, 32, 177-183.

[32] Keane, P.F. (1994) Characterisation of Biofilm and Encrustation on Ureteric Stents in Vivo. British Journal of Urology, 73, 687-691. https://doi.org/10.1111/j.1464-410X.1994.tb07557.x

[33] Ramsay, J.W., Gernham, A.J. and Mulhall, A.B. (1999) Biofilms, Bacteria and Blad- 
der Catheters. British Journal of Urology, 64, 395-398.

[34] Warren, J.W. (2001) Catheter-Associated Urinary Tract Infections. International Journal of Antimicrobial Agents, 17, 299-303.

[35] Stark, R.P. and Maki, D.G. (1984) Bacteriuria in the Catheterized Patient. What Quantitative Level of Bacteriuria Is Relevant? The New England Journal of Medicine, 311, 560-564. https://doi.org/10.1056/NEJM198408303110903

[36] Nickel, J.C., Olson, M.E., Barabas, A., Benediktsson, H., Dasgupta, M.K. and Costerton, J.W. (1990) Pathogenesis of Chronic Bacterial Prostatitis in an Animal Model. British Journal of Urology, 66, 47-54.

[37] Rosen, D.A., Hooton, T.M., Stamm, W.E., Humphrey, P.A. and Hultgren, S.J. (2007) Detection of Intracellular Bacterial Communities in Human Urinary Tract Infection. PLoS Med, 4, e329.

[38] Reid, G. (1999) Biofilms in Infectious Disease and on Medical Devices. International Journal of Antimicrobial Agents, 11, 223-226.

[39] Nickel, J.C., Olson, M., McLean, R.J., Grant, S.K. and Costerton, J.W. (1987) An Ecological Study of Infected Urinary Stone Genesis in an Animal Model. British Journal of Urology, 59, 21-30.

[40] Glaser, A. (2004) The Ubiquitous Triclosan. A Common Antibacterial Agaent Exposed. Pesticides and You, 34, 12-17.

[41] Schmid, M.B. and Kaplan, N. (2004) Reduced Triclosan Susceptibility in Methicillin-Resistant Stsphylococcus Epidermidis. Antimicrob. Agents Chemother, 48, 1397-1399. https://doi.org/10.1128/AAC.48.4.1397-1399.2004

[42] Nester, E.W. (2001) Microbiology a Human Persepective. McGraw-Hills, New York, 452.

[43] Stenson, J. (2002) Antibacterial Products May Fuel Growth of Superbugs. Health. http://www.anapsid.org/superbugs.html

[44] Desalva, S.J., Kong, B.M. and Lin, Y.J. (1996) Triclosan: A Safety Profile. American Journal of Dentistry, 185-196.

[45] Bhargava, H.N. and Leonard, P.A. (1996) Triclosan: A Safety Profilr. American Journal of Infection Control, 24, 209-218.

[46] Tulp, M.T. (1979) Metabolism of Chlorodiphenyl Ethers and Irgasan DP 300. Xenobiotica, 9, 65-77. https://doi.org/10.3109/00498257909038708

[47] Lyman, F.L. and Furia, T. (1969) Toxicology of 2,4,4,-Trichloro-2 Hydroxydiphenylether. IndMED, 38, 45-52.

[48] Levy, C.W. (1999) Molecular Basis of Triclosan Activity. Nature, 398, 383-384. https://doi.org/10.1038/18803

[49] McMurry, L.M., Oethinger, M. and Levy, S.B. (1998) Triclosan Targets Lipid Synthesis. Nature, 394, 531-532. https://doi.org/10.1038/28970

[50] Russell, A.D. (2014) Whiter Triclosan? Journal of Antimicrobial Chemotherapy, 8, 693-695.

[51] Balasurbramanian, A. (2012) Isolation and Identification of Uropathogens. Asian Pacific Journal of Tropical Biomedicine, 2, S1780-S1783.

[52] Christensen, G.D., Simpson, W.A., Younger, J.A., Baddour, L.M., Barrett, F.F., Melton, D.M. and Beachey, E.H. (1985) Adherence of Coagulase Negative Staphylococci to Plastic Tissue Culture a Quantitative Model for the Adherence of Staphylococci to Medical devices. Journal of Clinical Microbiology, 22, 996-1006.

[53] Kirby, A. (1966) Antibiotic Susceptibility Testing by a Standardized Disk Method. Journal of Clinical Pathology, 45, 493-496. 
Submit or recommend next manuscript to SCIRP and we will provide best service for you:

Accepting pre-submission inquiries through Email, Facebook, LinkedIn, Twitter, etc. A wide selection of journals (inclusive of 9 subjects, more than 200 journals)

Providing 24-hour high-quality service

User-friendly online submission system

Fair and swift peer-review system

Efficient typesetting and proofreading procedure

Display of the result of downloads and visits, as well as the number of cited articles Maximum dissemination of your research work

Submit your manuscript at: http://papersubmission.scirp.org/

Or contact ojmm@scirp.org 